\title{
Experimental Study on Reducing Motion of Circular Cylinder in Currents
}

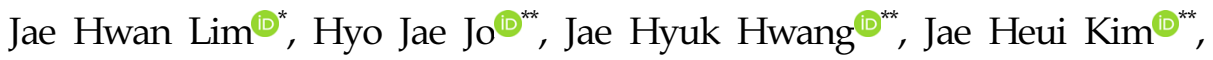 \\ Tae Kyung Lee $\circledast^{* *}$, Yoon Woo Choi $\circledast^{* *}$, Min Jun Lee $\circledast^{* *}$ and Young Kyu Kim $\circledast^{* *}$ \\ *Ocean Science and Technology School, Korea Maritime and Ocean University, Busan, Korea \\ *Division of Naval Architecture and Ocean Systems Engineering, Korea Maritime and Ocean University, Busan, Korea

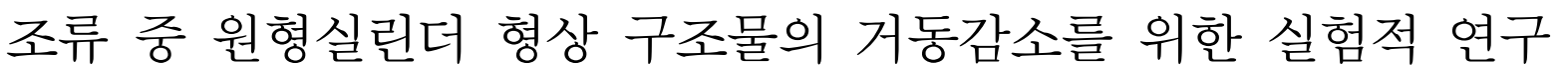 \\ 임재환(* \\ "한국해양대학교 해양과학기술전문대학원 \\ "한국해양대학교 조선해양시스템공학전공
}

KEY WORDS: Circular cylinder 원형실린더, VIM(Vortex induced motion)와 유기 운동, String 줄, In-line response 흐름 방향 응답, Cross flow response 흐름 직각 방향 응답, Model test 모형실험

\begin{abstract}
The development of marine technology is expected to increase the demand for marine plants because of increasing oil prices. Therefore, there is also expected to be an increase in the demand for cylindrical structures such as URF (umbilical, riser, flowline) structures and spars, which are used operating in various seas. However, a cylindrical structure experiences vortex induced motion (VIM) in a current. In particular, for risers and umbilicals, it is important to identify the characteristics of the VIM because interference between structures can occur. In addition, various studies have been conducted to reduce VIM because it is the cause of fatigue damage to structures. The helical strake, which was developed for VIM reduction, has an excellent VIM reduction performance, but is difficult to install on structures and has a negative effect on heave motion. Therefore, the purpose of this study was to supplement the shortcomings of the helical strake and develop a high-performance reduction device. In the reduction device developed in this study, a string is placed around the structure inside the flow, causing vibration. The vibration of this string causes a small turbulence in the flow field, reducing the VIM effect on the structure. Finally, in this study, the 2-DOF motion characteristics of models without a suppression device, models with a helical strake, and models with a string were investigated, and their reduction performances were compared through model tests.
\end{abstract}

\section{1. 서 론}

최근 지속적인 유가상승으로 인하여 해양플랜트 산업의 회복 에 대한 기대감이 높아지고 있고, 이에 따른 다양한 해양구조물 들의 수요 또한 증가할 것이라 예상된다. 실제로 해양구조물들 은 제작비용이 고가일 뿐만 아니라 유지 - 보수에도 상당한 비 용이 필요하다. 하지만 무엇보다 중요한 것은 2010년 GOM(Gulf of Mexico)에서 발생한 Deepwater horizon의 폭발사고와 같은 해 양사고가 반복되지 않도록 해양구조물의 신뢰성 있는 설계가 필요하다. 그리고 최근 심해 해양자원 개발의 확대로 인하여 설 치해역이 심해로 이동하고 있는 추세이다. 심해에서의 생산과 시추는 더 많은 부하와 스트레스를 유발하기 때문에 추가적인
엔지니어링 기술이 더욱 중요해지고 있다.

일반적으로 부유식 구조물을 대표하는 Spar, 시추를 위한 Riser, 수송을 위해 사용되는 Pipeline 등의 해양구조물은 기본적으로 원 형실린더 형상을 지니고 있다. 이러한 원형실린더 형상의 구조물 들은 일정한 속도 이상의 조류가 흐르는 경우, 후류에서 급격한 구배 변화로 인한 규칙적인 패턴의 와 흘림 현상(Vortex shedding) 이 발생하게 된다. 발생한 와 흘림 현상은 원형실린더 형상 구조 물에 주기적인 하중을 발생시키며, 구조물의 움직임과 상호작용 에 의해 와 유기 운동(Vortex induced motion, VIM)을 유발하는 원 인이 된다. VIM으로 인해 원형실린더 형상 구조물은 흐름에 평 행한 방향 응답(In-line response)과 흐름에 직각인 방향 응답 (Cross-flow response)이 발생하게 된다. 이러한 VIM 응답은 비선

Received 14 March 2019, revised 16 June 2019, accepted 12 August 2019

Corresponding author Hyo-Jae Jo: +82-51-410-4302, hjjo@kmou.ac.kr ORCID: https://orcid.org/0000-0002-7847-0462

(c) 2019, The Korean Society of Ocean Engineers

This is an open access article distributed under the terms of the creative commons attribution non-commercial license (http://creativecommons.org/licenses/by-nc/3.0) which permits unrestricted non-commercial use, distribution, and reproduction in any medium, provided the original work is properly cited. 
형적인 운동특성을 가지며, Vortex는 원형실린더 형상 구조물에 반복적인 하중을 유발하여 구조적 피로손상을 발생시킨다. 뿐 만 아니라 원형실린더 형상 구조물의 와 흘림 진동수(Vortex shedding frequency, $f_{s}$ )와 고유진동수(Natural frequency, $f_{n}$ )의 비 가 1 에 가까워지면 VIM 응답이 점점 커지게 되고, 두 진동수의 비가 1이 되면 공진현상의 일종인 Lock-in현상이 발생한다. 이러 한 이유로 VIM 응답은 원형실린더 형상 구조물의 설계 시 고려 해야할 중요한 인자이다.

따라서 구조물에 발생하는 VIM에 의한 영향을 줄이기 위하여 Helical strake와 같은 VIM 저감장치가 사용되고 있다. 그러나 Helical strake는 본체와 따로 제작하여 조립이 어렵고 고가의 시 공비가 발생한다(Son, 2010). 뿐만 아니라 구조물의 무게를 증가 시키며 Heave motion을 크게 만드는 단점이 존재한다(Oh, 2003). 그래서 기존의 Helical strake의 단점을 보완하고 우수한 저감성능 을 가진 저감장치를 개발하기 위한 연구가 진행되어 왔다. 먼저 Son(2010)은 원형실린더 형상 구조물에 필름을 부착함으로 유동 장에 위치한 필름이 유선형 형상을 만듦으로써 구조물에 작용하 는 수평력을 저감하는 실험적 연구를 진행하였다. 그리고 Jung and Yoon(2015)은 나선형 표면 처리를 한 트위스트 실린더의 $\mathrm{VIM}$ 저감성능에 대해서 $\mathrm{CFD}$ (Computational fluid dynamics) 해석 을 수행하였다.

앞서 진행된 선행연구처럼 VIM 응답과 관련된 연구는 크게 $\mathrm{CFD}$ 와 실험적 연구 두 가지 방법으로 이루어지고 있다. 먼저 $\mathrm{CFD}$ 의 경우는 원형실린더 형상 구조물의 경우 길이-직경비(이하 $L / D)$ 가 크기 때문에 계산량이 방대해지는 경향이 존재하며, 설치 해역의 수심이 깊어짐에 따라 해석의 어려움은 더욱 커지게 된 다. 따라서 최근에는 Full scale의 Riser 대신, Riser의 특정 Section 을 잘라서 사용하는 방법을 사용한다(Gustafsson, 2012). 하지만 $\mathrm{VIM}$ 응답은 점성이 지배적인 동적 응답이기 때문에 주로 실험을 통한 연구가 많이 이루어져 왔다. 그리고 기존의 VIM 응답과 관 련한 연구들은 Cross-flow 응답만을 고려한 1-DOF system에 관한 연구가 대다수 이루어졌으나, 최근 연구에서는 In-line 응답과 Cross-flow 응답을 동시에 고려하는 2-DOF system에 대한 실험들 이 수행되어지고 있다(Blevins, 2001; Bearman, 2011; Srinil et al., 2013; Kim et al. 2016; Park, 2017).

본 연구에서는 String이 조류환경 속에서 만들어내는 떨림이 유동장의 변화를 주는 메커니즘을 활용하여 VIM 저감을 위한 연 구를 수행하였다. 이와 유사한 사전연구로 Silva-Ortega and Assi
(2017)는 원형실린더 주변에 직경이 작은 8 개의 회전이 가능한 실린더를 배치하여 유동장에 변화를 주는 연구가 진행되었으며, 원형실린더에 작용하는 항력과 양력을 측정하였다. 그리고 SilvaOrtega and Assi(2018)에서는 작은 실린더의 개수, 실린더의 직경 비, 설치위치를 파라미터로 설정하여 항력과 양력에 관한 연구를 진행하였다. 마찬가지로 선행연구로 진행되었던, Baek et al. (2018)은 String을 저감장치로 사용하여 String의 떨림을 이용한 항력과 수평력의 저감성능에 대한 실험적 연구를 진행하였다. 앞 서 연구경향과 방법들을 종합하여 본 연구는 2-DOF 환경에서 실 험을 통해서 진행하였으며, 원형실린더가 조류 중 움직임으로 인 한 비선형적인 특성을 파악하기 위해 VIM 응답의 변위에 초점을 두었다. 그리고 실험에 사용된 모델은 크게 네 종류로 저감장치 를 부착하지 않은 Bare hull 모델, Helical strake를 부착한 모델, Two string을 부착한 모델과 방사형으로 String이 설치된 모델로 정하였다. 최종적으로 각 모델별 VIM 응답 특성을 파악하면서 $\mathrm{VIM}$ 의 저감성능을 비교 및 분석하였다.

\section{2. 모형 실험}

\section{1 실험환경}

Fig. 1은 연구에서 사용된 실험장비들을 나타내고 있다. 먼저 실 험은 한국해양대학교에 있는 회류수조(Circulating water channel, $\mathrm{CWC}$ )에서 실시하였다. 그리고 회류수조의 크기는 $4.0 \times 1.8 \times 1.2 \mathrm{~m}$ $\left(L_{c w c} \times B_{c w c} \times D_{c w c}\right)$ 이며, 측정수심은 $0.915 \mathrm{~m}$ 로 설정하였다. $\mathrm{VIM}$ 응답의 측정은 비접촉식 3 차원 운동계측기를 사용하였으며, 이는 실험모델이 반사하는 빛을 마커로 인식하는 광학용 계측기이다. 따라서 실험모델에 빛을 반사할 수 있는 마커를 실험모델의 무게 중심점에 부착하여 VIM 응답의 변위를 측정하였다.

Fig. 2의 왼쪽 그림은 실험의 전체적인 모식도를 나타내고 있 다. 먼저 원형실린더 구조물의 $x, y$ 변위를 측정하기 위해 프레임 의 상단부에 유니버셜 조인트를 설치하였다. 유니버셜 조인트와 모델을 이어주는 봉은 알루미늄으로 $2.6 \mathrm{~m}$ 의 길이로 제작되었으 며, 이는 원형 실린더의 회전운동을 최소화하기 위함이다. 여기 서 $x$ 방향은 회류수조의 길이방향으로 유속은 왼쪽에서 오른쪽 으로 진행방향을 가지고 있으며, $y$ 방향은 회류수조의 벽면방향 이다. 여기에 $x, y$ 방향으로 일정한 복원력을 제공하기 위해서 스 프링을 설치하였다. 그리고 Fig. 2의 오른쪽 그림은 실험에 사용 된 실험모델의 모식도를 나타내었고 Table 1에는 모델별 제원을
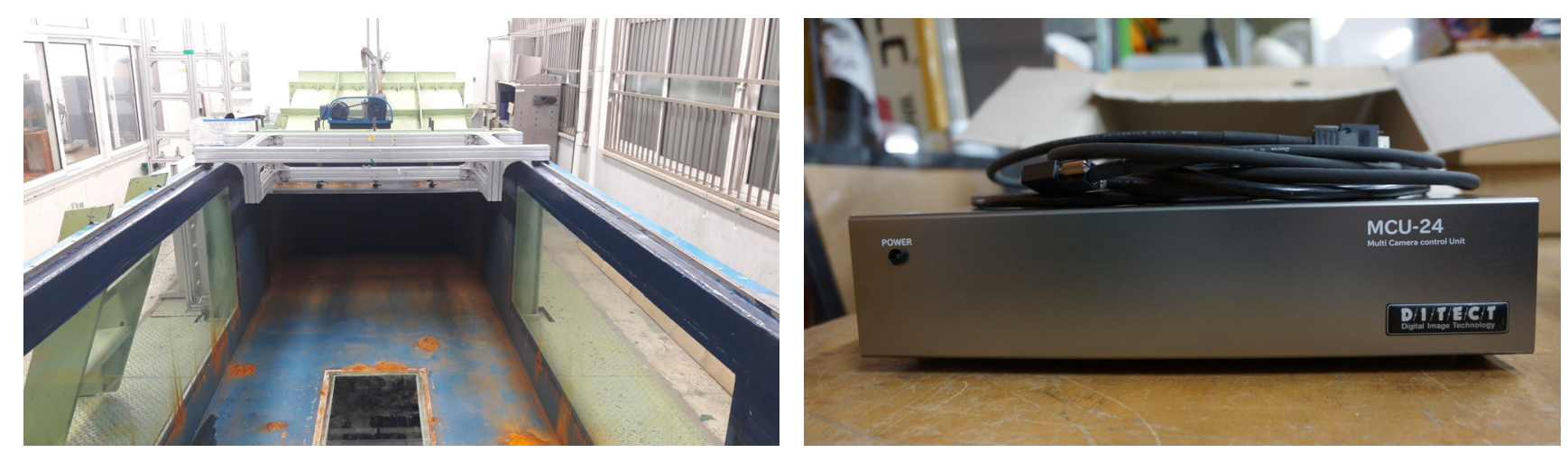

Fig. 1 Circulating water channel (left) \& 3-D motion measuring instrument (right) 

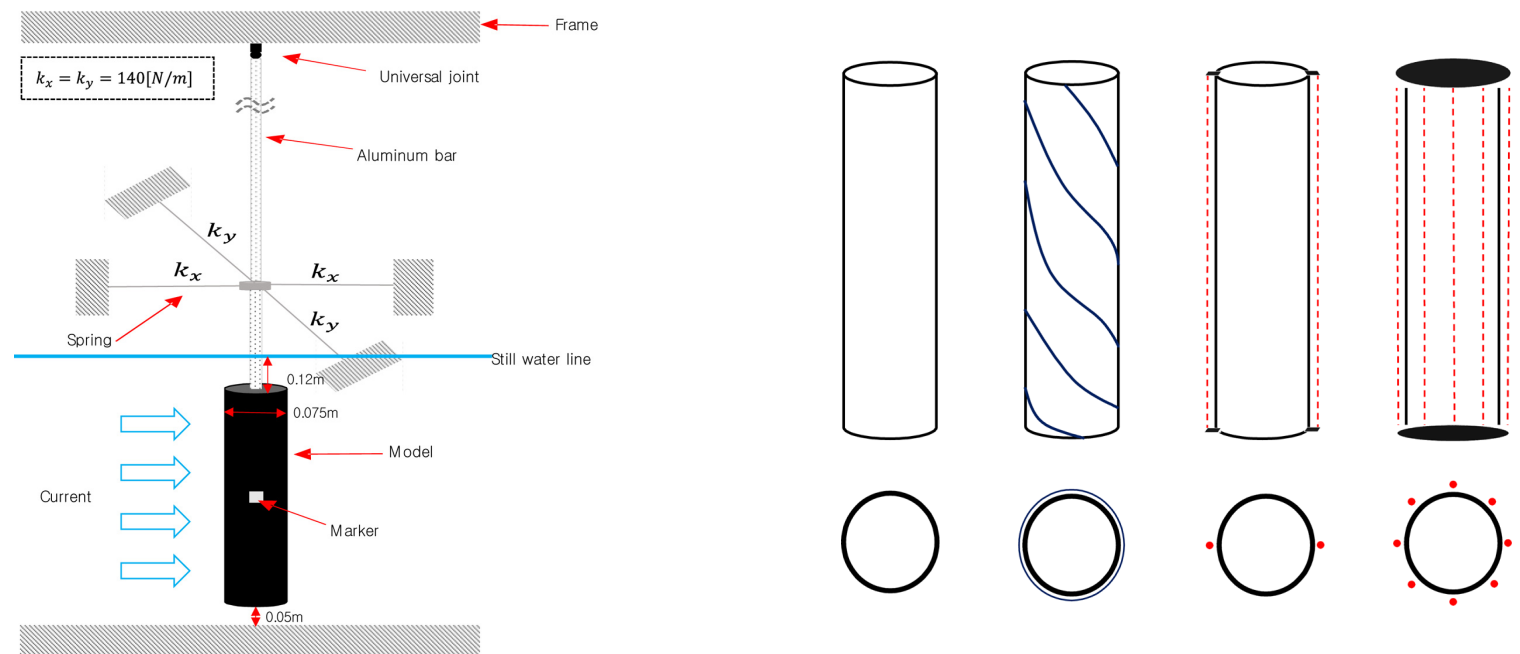

Fig. 2 Concept of experiment (left) \& Experimental model figures (right)

Table 1 Experimental model

\begin{tabular}{ccc}
\hline \hline Case & Material & Description \\
\hline \multirow{2}{*}{ Bare } & Body: Acrylic & Diameter $(D): 0.075[\mathrm{~m}]$ \\
& & Length $(L): 0.75[\mathrm{~m}]$ \\
Strake & Body: Acrylic & Height of strake : $0.1 \mathrm{D}$ \\
& Strake: Acrylic & Picth of strkae : $11.5 \mathrm{D}$ \\
Two strings & Body: Acrylic & Number of strake : 3 \\
& String: Nickel & String's natural frequency : $50[\mathrm{~Hz}]$ \\
Radiational string & Body: Acrylic & Each string's natural frequency : $50[\mathrm{~Hz}]$ \\
& String: Nickel & Number of string : 8 \\
\hline
\end{tabular}
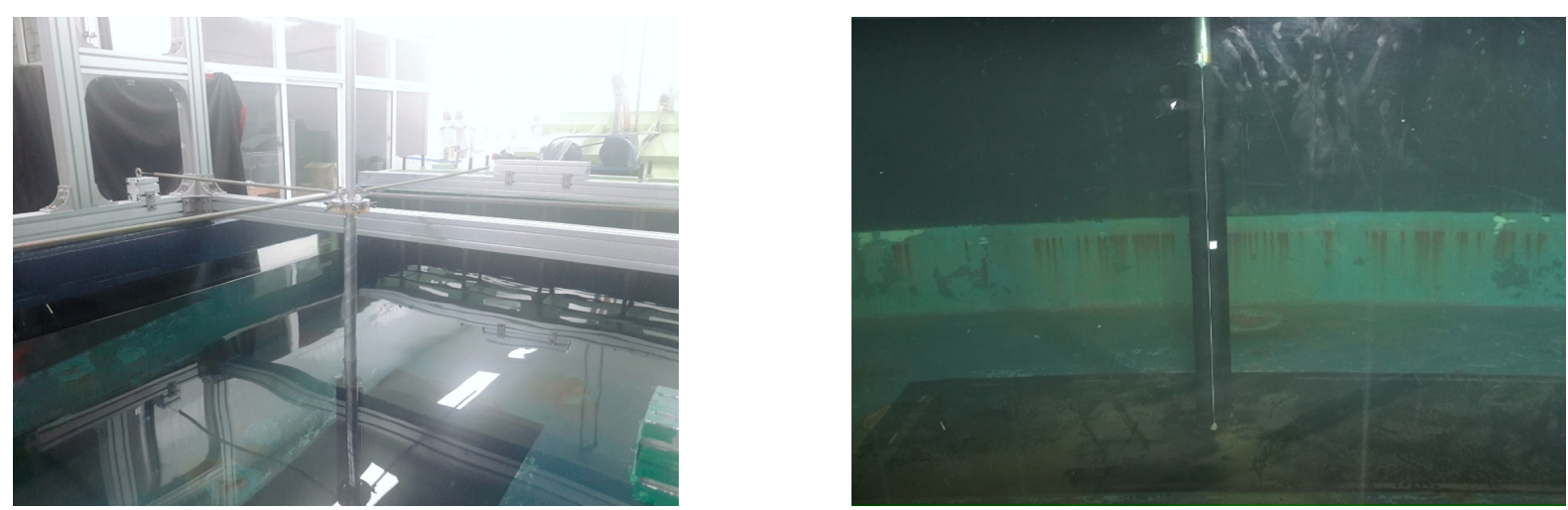

Fig. 3 Installation condition (left) \& Experiment for two string case (right)

나타내었다. 첫 번째로 가장 왼쪽에 있는 실험모델은 저감장치 를 부착하지 않은 Bare case(이하 Bare)이며, VIM 저감성능을 비 교하기 위한 기준이 되는 구조물이다. Bare는 원형실린더 형상의 구조물이며, 길이는 $0.75 \mathrm{~m}$ 로 제작되었고 직경은 벽면효과를 최 소화하기 위해 $0.075 \mathrm{~m}$ 이며, $L / D=10$ 으로 설정하였다. Bare의 바 로 오른쪽에 위치한 모식도는 선행기술을 대표할 수 있는 Strake case(이하 Strake)이다. Strake의 경우 Bare에 Helical strake를 부착 하였으며, Strake의 제원은 선행자료를 참고하여 제작하였다 (Blevins, 2001). 그리고 Strake의 오른쪽에 위한 모델은 선행연구 에서 고안된 Two strings case(이하 String)이며, 흐름의 방향에 수 직하게 $180^{\circ}$ 간격으로 String을 설치하였다. 끝으로 가장 오른쪽
에 위치한 모델은 이번 연구에서 새롭게 고안한 Radiational string case(이하 Radiation)이며, 원 둘레를 따라서 $45^{\circ}$ 간격으로 총 8개의 String을 설치하였다. Fig. 3은 본 연구의 실제 실험사진 을 나타내었으며, 전체적인 설치사진과 Two string 모델에 대한 실험 광경을 나타내고 있다.

\section{2 실험조건 및 방법}

본 연구에서 실험유속은 $0.3 \mathrm{~m} / \mathrm{s}$ 부터 $1.2 \mathrm{~m} / \mathrm{s}$ 까지 $0.1 \mathrm{~m} / \mathrm{s}$ 간격으 로 설정하였다. 또한 모형실험의 결과를 일반화하기 위하여 무 차원 파라미터를 사용하였다. 첫 번째 사용된 파라미터로 구조 물의 고유 진동수 $\left(f_{n}\right)$, 유속, 직경으로 표현되된다. 최종적으로 
구조물의 고유 진동속도와 유속의 비로 표현되는 무차원 속도 인 Reduced velocity $\left(V_{r}\right)$ 를 사용하였으며, 실험유속에 따라 $V_{r}$ 은 4.45 18.0에 형성되었다. $V_{r}$ 은 식 (1)과 같이 나타낼 수 있다.

$$
V_{r}=\frac{U}{f_{n} D}
$$

이때 구조물의 고유 진동수는 식 (2)와 같이 나타낼 수 있다. 본 실험에서 고유 진동수는 자유 감쇠 실험을 통하여 구하였으 며, 부가질량의 영향을 최소화하기 위해서 공기 중에서 실시하 였다.

$$
f_{n}=\frac{1}{2 \pi} \sqrt{\frac{k}{m+m_{a}}}(\text { air })
$$

$m_{a}:$ Added mass $[\mathrm{kg}]$

$k:$ Stiffness of system $\left[\mathrm{kg} / \mathrm{s}^{2}\right]$

두 번째 파라미터로 VIM 응답은 점성이 지배적인 현상이므 로 관성력과 점성력의 관계를 나타내주는 무차원수인 Reynolds $\operatorname{number}(R e)$ 를 사용하였고, 식 (3)으로 나타내었다. 본 실험에서 는 와류가 활발히 일어나는 아임계 영역인 22,500 90,000 범위 에서 형성되었다.

$$
\begin{aligned}
& R e=\frac{U D}{\nu} \\
& U: \text { Flow velocity }[\mathrm{m} / \mathrm{s}] \\
& D: \text { Diameter }[\mathrm{m}] \\
& \nu: \text { kinematic viscosity }\left[\mathrm{kg} / \mathrm{s}^{2}\right]
\end{aligned}
$$

세 번째는 진동하는 구조물의 응답의 메커니즘을 일반화하기 위하여 Strouhal number $(S t)$ 를 사용하였으며, Bare에 대해서 전 체적으로 약 0.2 의 값을 가지고 있었다. St는 와 흘림 진동수 $\left(f_{s}\right)$ 와 구조물의 직경, 유속의 조합으로 식 (4)과 같이 나타낼 수 있다. 이 때 $S t$ 에 사용되는 와 흘림 진동수 $\left(f_{s}\right)$ 는 실험을 통 해서 얻어진 값을 사용하였다.

$$
S t=\frac{f_{s} D}{U}
$$

$$
\begin{aligned}
& U: \text { Flow velocity }[\mathrm{m} / \mathrm{s}] \\
& D: \text { Diameter }[\mathrm{m}]
\end{aligned}
$$$$
f_{s} \text { : Vortex shedding frequency }[\mathrm{Hz}]
$$

끝으로 VIM 응답에 영향을 주는 요인인 Mass $\operatorname{ratio}(\bar{m})$ 의 경 우 모든 Case에 대해서 $\bar{m}=1.1$ 로 동일한 조건에서 실험을 진행 함으로써 관성력의 영향을 동일하게 하였으며, 식 (5)와 같이 나타낼 수 있다.

$$
\bar{m}=\frac{4 m}{\rho \pi D^{2} L}
$$

직립인 상태에서 원형실린더 형상 구조물의 VIM 운동응답특 성을 파악하기 위하여 In-line 응답 방향의 용수철의 강성과 Cross-flow 응답 방향의 스프링의 강성은 $140[\mathrm{~N} / \mathrm{m}]$ 로 동일하게 설정해주었다. 끝으로 실험 계측 시간은 실험모델의 운동을 안 정한 상태에서 계측하기 위하여 각 유속별로 300 초로 하였고, 균일류를 얻기 위한 충분한 대기시간을 가졌다. 뿐만 아니라 동 일 유속에서 계측의 불확실성을 감소하기 위하여 Case별로 3회 반복 실험을 실시하였다.

\section{3. 실험결과 및 고찰}

\subsection{In-line amplitude}

Fig. 4의 그래프는 $V_{r}$ 변화에 따른 In-line amplitude의 평균값을 실린더의 직경으로 무차원화하여 비교한 그래프이다. Bare는 검 은색 원형 표식으로 나타내었고, Strake는 붉은색 사각형 표식, String은 푸른색 삼각형 표식, Radiation은 녹색 다각형 표식으로 나타내었다. Fig. 4(a)에 의하면, 대부분의 유속에 있어서 Strake 는 In-line amplitude를 감소시키는 것을 알 수 있다. 그러나 $V_{r}=12$ 인 유속에서는 Strake의 경우가 Bare보다 미세하게 크게 나타나는 경향을 알 수 있다. 그리고 Fig. 4(b)에 의하면, String의 In-line amplitude는 Strake와 Radiation에 비해 다소 크게 나타나지

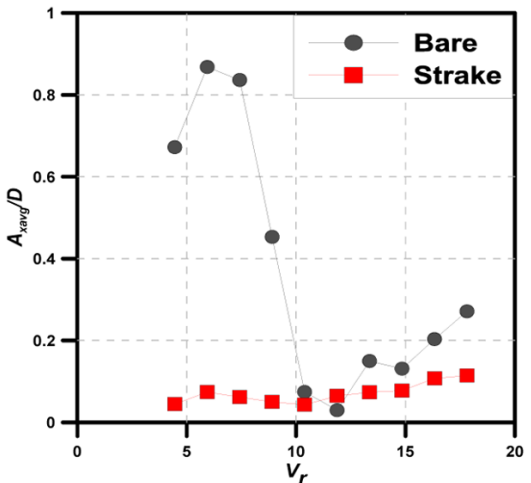

(a) Strake

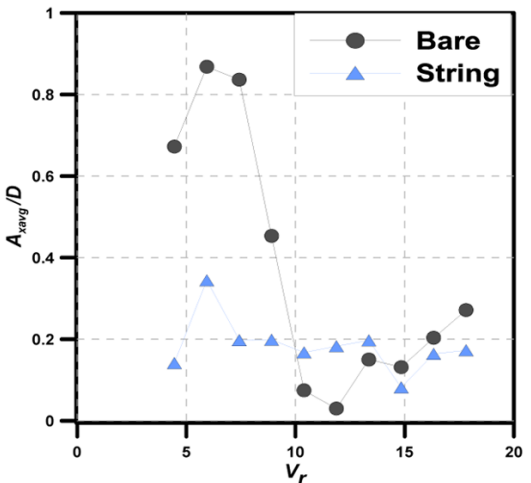

(b) String

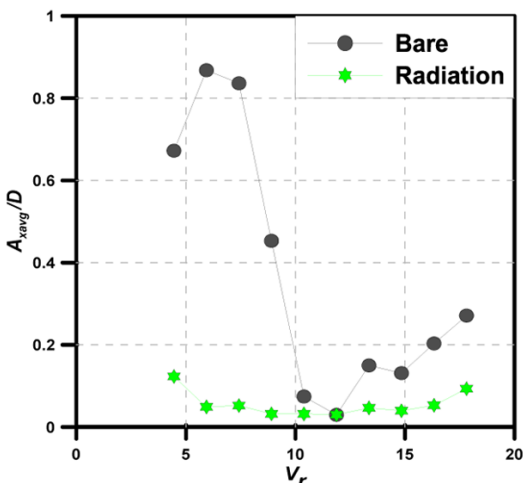

(c) Radiation

Fig. 4 Comparisons of in-line amplitude 


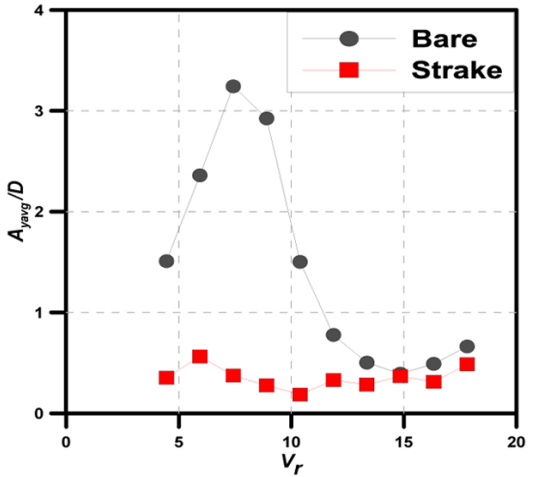

(a) Strake

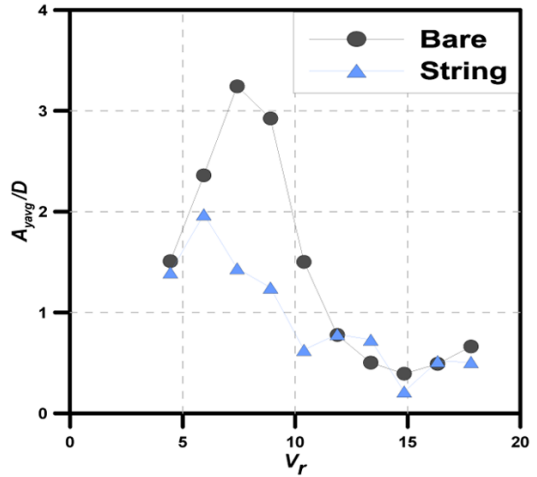

(b) String

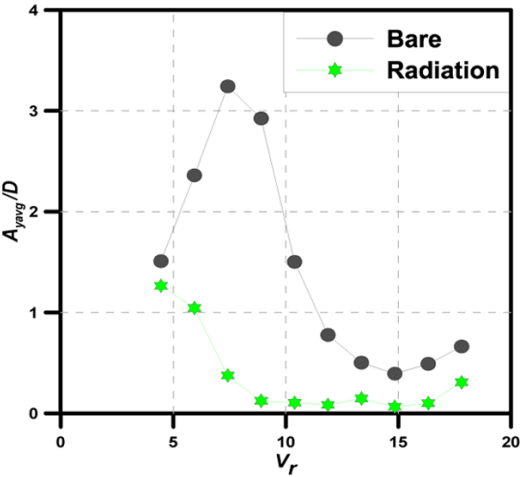

(c) Radiation

Fig. 5 Comparisons of cross-flow amplitude

만, $10.5 \leq V_{r} \leq 13.5$ 인 구간을 제외하면 Bare보다 작은 값을 가 지는 것을 알 수 있다. 끝으로 Fig. 4(c)에서는, Radiation은 Bare 에 비해 전 유속에서 In-line amplitude의 크기가 감소되었음을 확 인 할 수 있다.

\subsection{Cross-flow amplitude}

Fig. 5의 그래프는 $V_{r}$ 변화에 따른 Cross-flow amplitude의 평균 값을 실린더의 직경으로 무차원화하여 비교한 그래프이다. Fig. 5(a)에 의하면, Strake는 전체 유속에서 Cross-flow amplitude가 Bare보다 작게 나타나는 것을 알 수 있다. 그리고 Fig. 5(b)를 보 면, In-line amplitude의 경향과 마찬가지로 String은 Strake와 Radiation에 비해 Cross-flow amplitude는 크게 나타나는 것을 확 인할 수 있다. 하지만 Bare와 비교해보면, $V_{r}$ 이 13.5에서는 미소 하게 큰 진폭이 발생하는 구간을 제외한 전반적인 유속에 걸쳐 진폭이 감소되었음을 알 수 있다. Fig. 5(c)에서 Radiation은 $V_{r}$ 이 4.45 에서 진폭의 차이는 미소하였으나, 모든 유속에서 진폭 이 확실히 저감되었음을 확인할 수 있다.

\subsection{In-line \& Cross-flow motion response}

Fig. 6에는 $V_{r}$ 별로 In-line과 Cross-flow의 응답을 종합하여 나
타내었으며, 응답의 형상은 발생하는 진폭의 최대치에 의해 형 성된다. 먼저 Bare의 응답은 $4.45 \leq V_{r} \leq 7.5$ 인 구간에서 기울어 진 8 자 모양의 운동을 하고 있으며, $7.5 \leq V_{r} \leq 12.0$ 까지는 직립 8 자 운동을 하고 있다. 그리고 $V_{r} \geq 13.35$ 인 구간부터 8 자 운동 의 경향이 사라지고, 점 운동을 하는 것을 관찰할 수 있다. 첫 번 째로 Strake의 응답을 보면, Bare의 8자 운동의 경향은 나타나지 않으며 전체 유속에서 In-line 응답이 줄어듦을 관찰할 수 있다. 그리고 Cross-flow 응답의 경우, $V_{r} \leq 12$ 의 범위에서는 유속별로 응답의 크기가 작음을 확인할 수 있으나, $V_{r} \geq 12$ 인 구간에서 응 답의 크기는 Bare와 유사한 점을 보아 저감성능을 관찰하기 어 려웠다. 그리고 String의 응답은 Strake와 마찬가지로 Bare의 8자 운동 경향은 눈에 띄지 않는다. 그러나 String의 In-line 응답은 Bare와 큰 차이를 보이지 않으며, Cross-flow 응답은 $V_{r}$ 이 7.42, 8.9에서만 작음을 알 수 있다. 끝으로 Radiation은 $V_{r}$ 이 4.45, 5.93 에서는 약하게 8 자 모양의 운동을 가지는 것으로 확인되었고, Bare에 비해 전체 유속에 걸쳐 In-line 응답과 Cross-flow 응답 크 기 또한 확연하게 줄어든 모습을 확인할 수 있다.

Fig. 5에 의하면, String은 Strake와 Radiation에 비해 저감성능 이 미미하다는 사실을 확인할 수 있다. 따라서 Fig. 7에는 $V_{r}$ 에

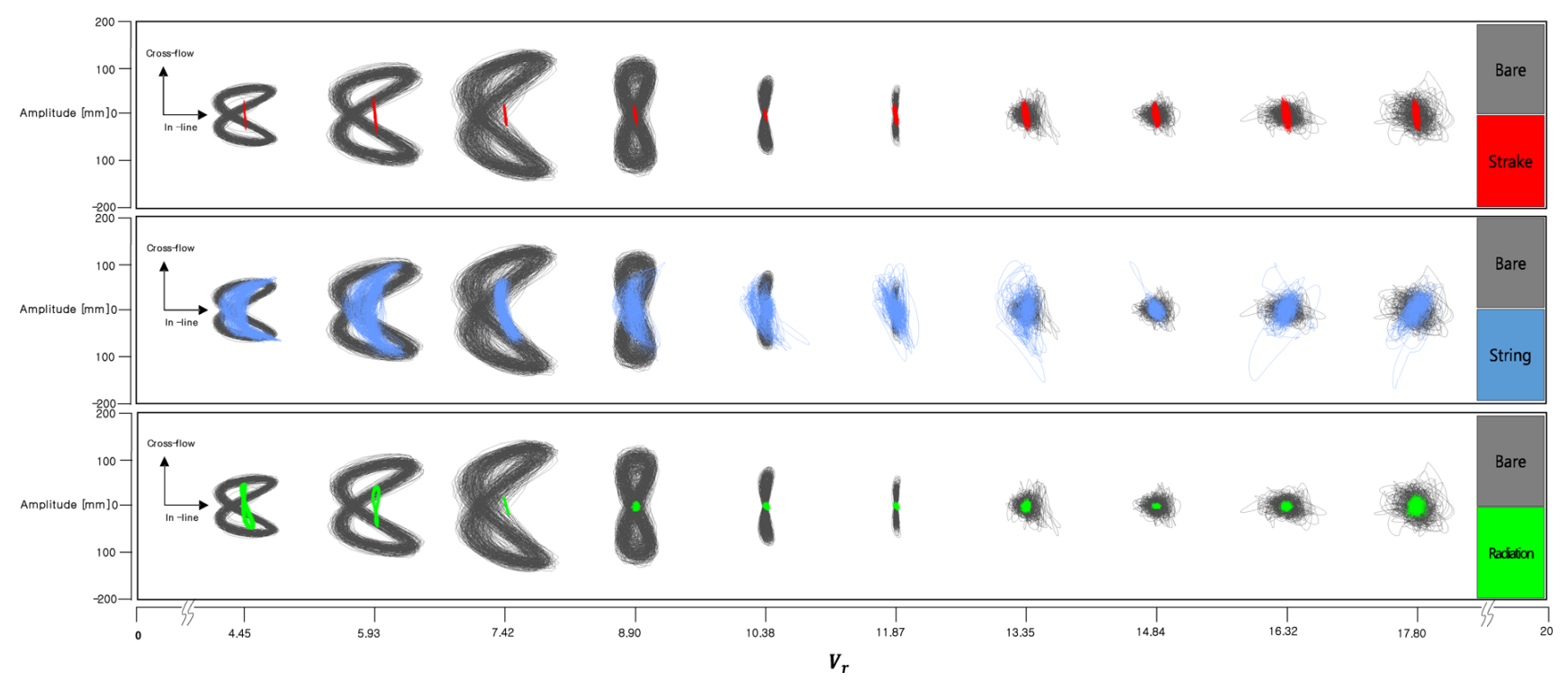

Fig. 6 Comparisons of motion response 


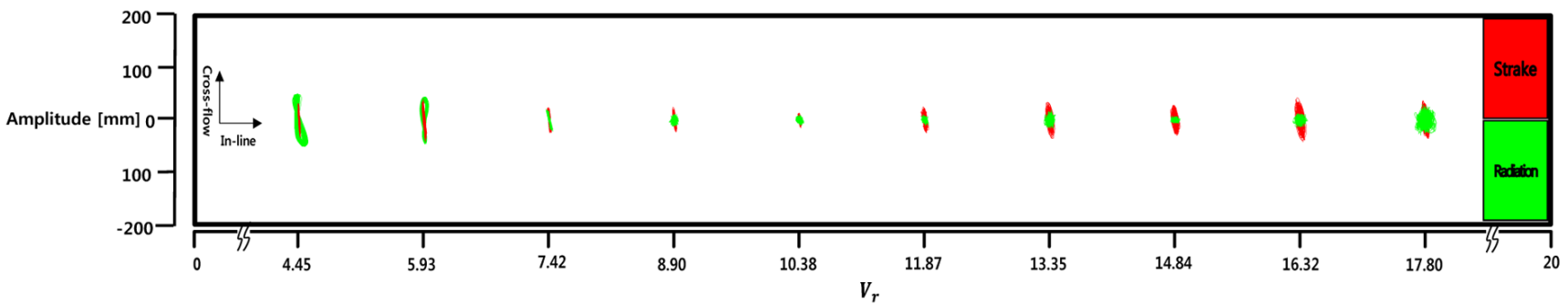

Fig. 7 Comparisons of motion response (Strake vs Radiation)

따른 Strake와 Radiation의 응답을 비교하였다. Radiation과 Strake 의 응답은 $V_{r}$ 이 $4.45,4.5 \leq V_{r} \leq 12.0,12.0 \leq V_{r} \leq 17.8$ 세 구간 으로 나누어서 비교를 하였다. 첫 번째 구간인 $V_{r}$ 이 4.45 인 유속 에서는 Strake가 Radiation보다 In-line 응답과 Cross-flow 응답이 작음을 확인할 수 있다. 그리고 두 번째 구간인 $4.5 \leq V_{r} \leq 12.0$ 에서 In-line 응답은 큰 차이를 보이지 않지만, Cross-flow 응답은 Radiation이 작은 것으로 관찰되었다. 그리고 세 번째 구간인 $12.0 \leq V_{r} \leq 17.8$ 에서는 In-line 응답의 크기가 유사하였고, Crossflow 응답의 경우, Radiation이 Strake보다 크기가 작은 것을 확인 할 수 있다. 따라서 전체 유속에서 걸쳐서 In-line 응답 측면에서 는 Radiation과 Strake가 유사한 응답의 크기를 보이고 있으나, Cross-flow 응답의 측면에서 바라보았을 때에는 Radiation이 Strake보다 작은 응답의 크기를 보여주고 있다. 이는 유속이 증가
할수록 Radiation이 Strake에 비해 뚜렷한 VIM 저감성능을 보여 주고 있음을 알 수 있다.

\subsection{Distribution table of in-line amplitude}

VIM 응답은 항상 일정한 크기의 진폭을 가진 운동이 아니기 때문에 다양한 크기의 진폭이 발생한다. 위의 $3.1,3.2,3.3$ 에 나 타낸 결과들은 VIM 응답의 불규칙한 진폭을 표현하기에는 한 계가 존재한다. 따라서 Fig. 7에는 $V_{r}$ 이 8.9인 유속에서 횡축을 In-line amplitude, 종축을 빈도로 한 도수분포표를 이용하여 저 감성능을 비교하였다. Bare의 경우, 진폭의 크기가 $20 ~ 50 \mathrm{~mm}$ 범 위에 형성되어 있었고, Fig. 8(a)를 살펴보면 Strake의 진폭은 0 10mm사이에서 발생하고 있다. Fig. 8(b)에서는 String의 진폭 이 0 30mm 범위에서 관찰되었으며, 일정부분 Bare와 겹치는 부

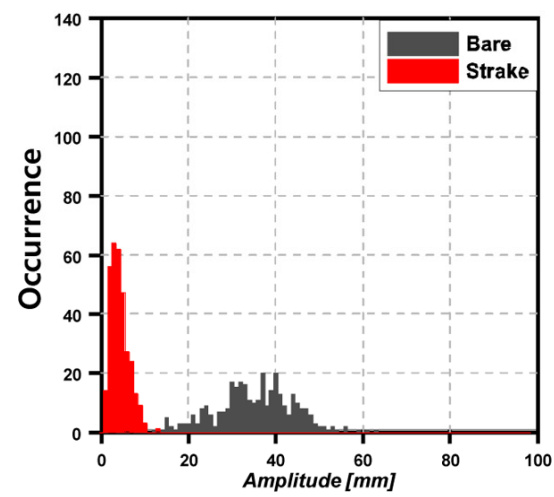

(a) Strake

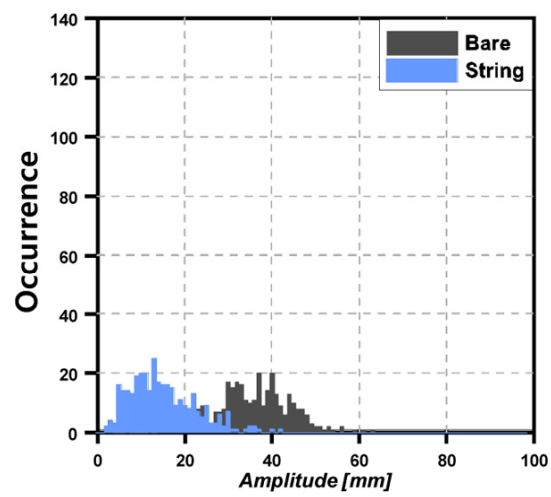

(b) String

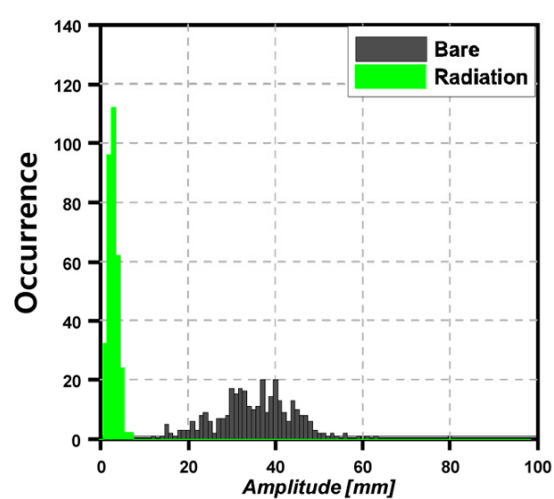

(c) Radiation

Fig. 8 Comparisons about distribution table of in-line amplitude at $V_{r}=8.9$

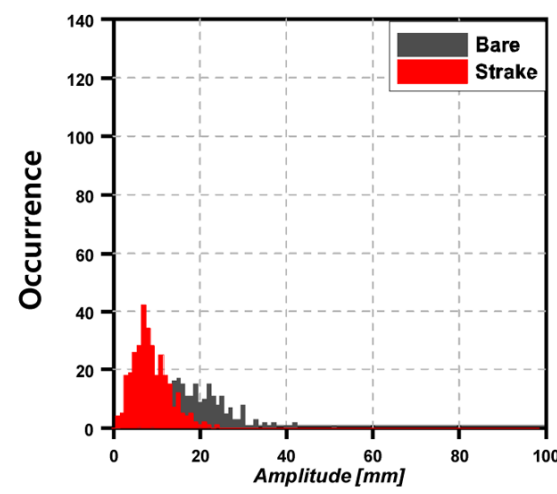

(a) Strake

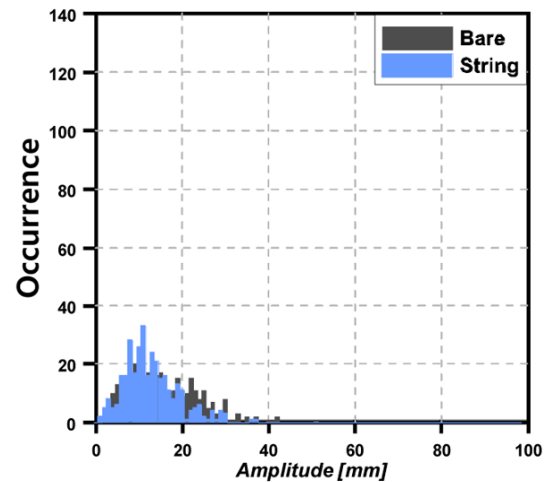

(b) String

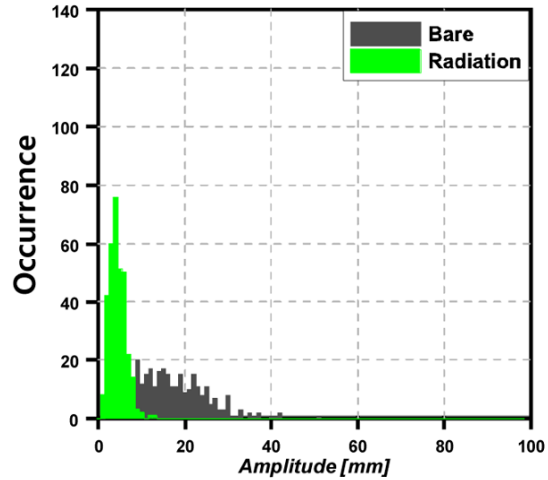

(c) Radiation

Fig. 9 Comparisons about distribution table of in-line amplitude at $V_{r}=16.92$ 
분이 발생한 것 또한 확인할 수 있다. 마지막으로 Fig. 8(c)의 Radiation은 Strake와 마찬가지로 $0 \sim 10 \mathrm{~mm}$ 에서 진폭이 발생하는 것을 확인할 수 있었으며, Strake, String과는 달리 특정 진폭에 서 빈도가 집중되어 있음을 알 수 있다.

Fig. 9에는 Fig. 8과 마찬가지로 $V_{r}$ 이 16.32인 유속에서 도수 분포표를 이용하여 저감성능을 비교하였다. Fig. 9(a)에 의하면, Bare의 진폭은 $0 \sim 30 \mathrm{~mm}$ 범위에서 형성되었으며, Strake는 $0 \sim 20 \mathrm{~mm}$ 사이의 진폭들이 발생하고 있음을 알 수 있다. 뿐만 아 니라 Bare와 Strake의 진폭의 범위가 일정 부분 겹치는 것을 알 수 있다. 그리고 Fig. 9(b)에서는 String이 Bare와 진폭의 범위와 발생빈도가 상당 부분 일치하고 있어, 저감의 정도가 미미하다 는 것을 알 수 있다. 끝으로 Fig. 9(c)에서의 Radiation은 0 10mm 에서 진폭이 발생하고 있는 점으로 보아 전반적으로 Strake와 Radiation은 진폭의 범위와 빈도수를 바탕으로 저감성능을 파악 할 수 있었다. 그리고 $0 \sim 20 \mathrm{~mm}$ 사이의 범위를 가졌던 Strake에 비해 0 10mm 범위를 가지는 Radiation이 우수한 저감성능을 보 여주고 있다고 판단된다. 뿐만 아니라 Radiation의 경우, $V_{r}$ 이 8.9 에서 보여주었던 경향과 유사하게 특정 빈도수가 집중되어 있음을 확인할 수 있다.

\subsection{Distribution table of Cross-flow amplitude}

Fig. 10에는 $V_{r}$ 이 8.9인 유속에서 횡축을 Cross-flow amplitude, 종축을 빈도로 한 도수분포표를 이용하여 저감성능을 비교하였
다. Bare는 약 $170 ~ 270 \mathrm{~mm}$ 사이의 진폭이 발생하였고, 이는 가 장 큰 진폭과 가장 작은 진폭의 크기 차이가 $100 \mathrm{~mm}$ 정도 발생 하였음을 의미한다. Fig. 10(a)의 Strake는 0 50mm 범위에서 진 폭이 발생함을 알 수 있다. 그리고 Fig. 10(b)에서 String은 0 170mm의 범위에서 고르게 빈도를 가지고 있음을 알 수 있다. Fig. 10 (c)를 살펴보면 Radiation의 경우 $0 \sim 25 \mathrm{~mm}$ 사이의 진폭이 발생함을 관찰할 수 있으며 In-line 응답의 경향과 마찬가지로 특정 진폭이 집중되어 발생하는 것을 확인할 수 있다. 따라서 $V_{r}$ 이 8.9에서 Strake, String, Radiation은 Cross-flow 응답 감소에 긍정적인 영향을 끼쳤으며, String보다 Strake와 Radiation이 저감 성능이 우수하다는 것을 알 수 있다.

Fig. 11에는 $V_{r}$ 이 16.32인 유속에서 도수분포표를 바탕으로 저감성능을 비교하였다. Bare는 약 0 70mm 범위에서 진폭이 형 성되었다. Fig. 11(a)에 의하면, Strake 경우 진폭의 발생 범위는 0 70mm으로 Bare와 동일하였으나, 보다 낮은 진폭에서 높은 집 중도를 가지고 있는 점으로 보아 미미하게 저감성능을 확인할 수 있었다 하지만 Fig. 11(b)의 String은 Bare의 진폭범위와 거의 동일한 범위가 관찰되어 저감성능을 관찰할 수가 없었다. 하지 만 Fig. 11(c)의 Radiation을 살펴보면 0 25mm범위의 진폭이 발 생하였으며, 마찬가지로 특정 진폭에서 높은 집중도를 보여주 고 있다. 따라서 $V_{r}$ 이 8.9에서와 마찬가지로 $V_{r}$ 이 16.32에서 또 한 Strake와 String보다 Radiation이 저감성능이 우수하다는 것을 알 수 있다.

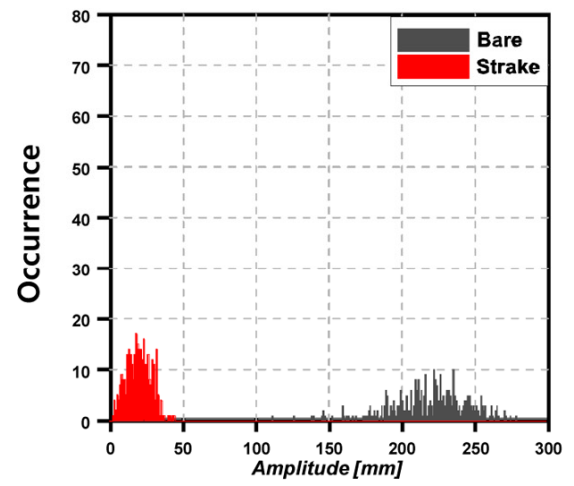

(a) Strake

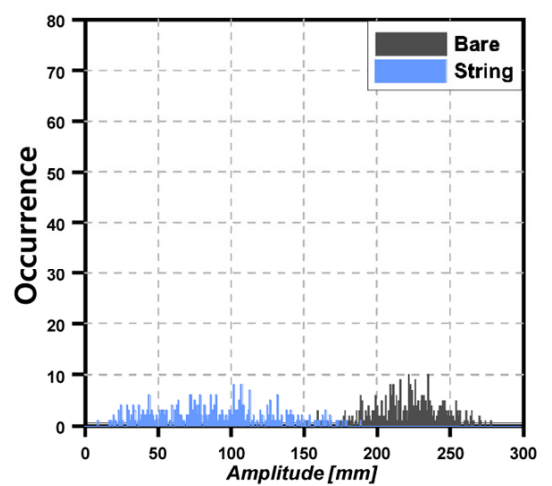

(b) String

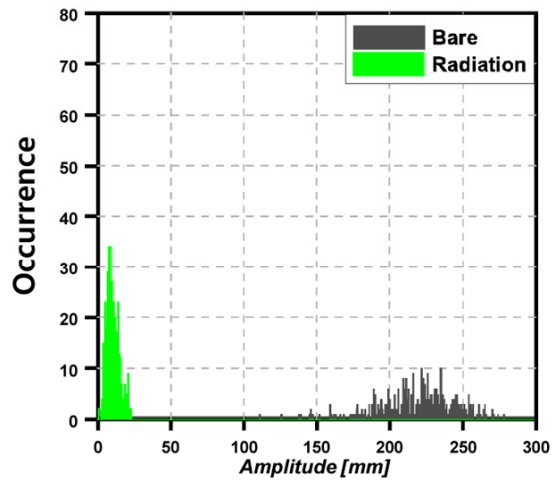

(c) Radiation

Fig. 10 Comparisons about distribution table of cross-flow amplitude at $V_{r}=8.9$

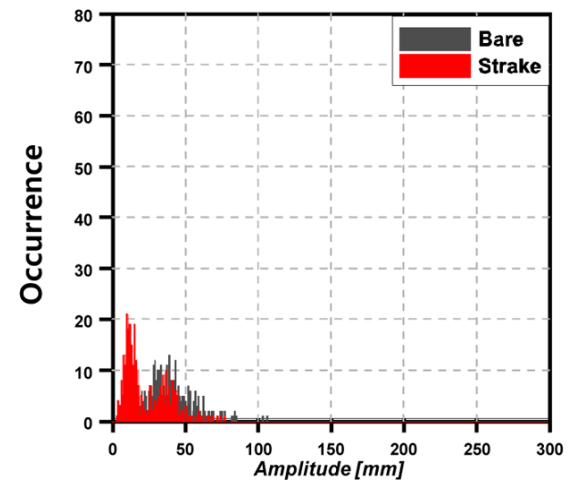

(a) String

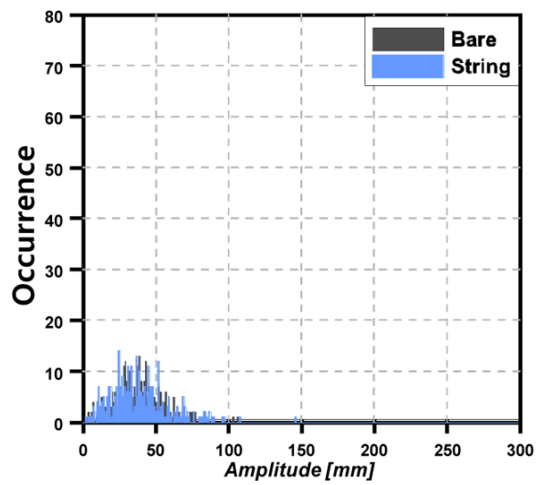

(b) String

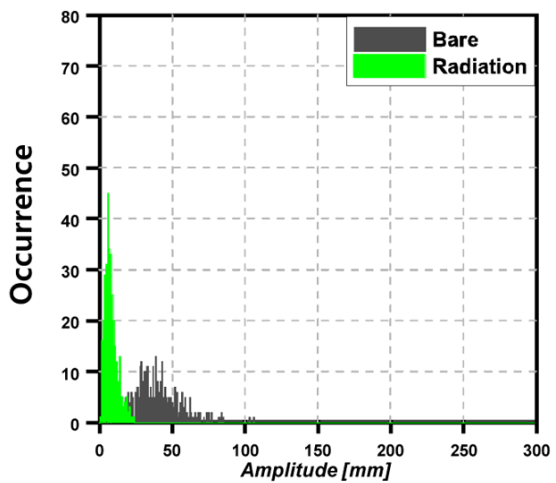

(c) Radiation

Fig. 11 Comparisons about distribution table of cross-flow amplitude at $V_{r}=16.92$ 


\section{4. 결 론}

본 논문에서는 모형 실험을 통한 원형실린더 형상 구조물에 작 용하는 VIM 응답의 저감에 관한 연구를 진행하였다. 모형 실험 모델은 Bare, Strake, String, Radiation로 선정하였고, 동일한 실험 조건에서 VIM 응답의 Average amplitude, Response, Distribution table을 활용하여 실험결과를 나타내었고 최종적으로 아래와 같은 결론을 얻을 수 있다.

(1) 저감장치를 부착한 모델에서도 특정 유속에서 8 자 운동이 관찰되었으나 Bare보다 운동 응답의 크기가 작음을 확인할 수 있다.

(2) 진폭의 도수분포표를 바탕으로 Radiation의 VIM 응답은 특정 진폭에서 높은 집중도를 보이고 있다. 이는 원형실린더 형 상 구조물을 설계 시, 원형실린더 형상 구조물의 간섭에 관련하 여 중요한 요인으로 고려될 수 있을 것이라 판단된다.

(3) Strake 모델은 $V_{r}$ 가 4.45 과 5.93 인 구간에서는 응답의 크 기가 작음을 볼 수 있었다. 그러나 $V_{r}$ 이 7.42 이상인 유속 범위 부터 17.8까지 유속이 증가할수록 저감효과를 관찰할 수 있었 다. 반해 Radiation의 경우 $V_{r}$ 이 4.45와 5.93에서는 Strake에 비 해 상대적으로 응답의 크기가 큰 것을 알 수 있었지만 $V_{r}$ 이 증 가할수록 뚜렷한 저감효과를 관찰할 수 있다.

(4) Strake는 곡가공 공정과 부착 시 용접 기술이 필요하지만, Radiation의 경우 String을 상하단부에 고정하기 위한 Winch 혹 은 고정장치만 필요하다는 점에서 Strake 단점을 보완함과 동시 에 우수한 VIM 저감성능을 가진 기술이라 판단된다.

\section{후 기}

본 연구는 한국해양대학교 $\mathrm{LINC}+$ 사업단의 지원으로 수행된 연구결과 중 일부임을 밝히며, 연구비 지원에 감사드립니다.

\section{References}

Baek, D.-I., Jo, H.-J., Lee, M.-J., Lim, J.-H., Lee, T.-K., Kim, J.-H., Oh, T.-W., 2018. Experimental Study on Reducing Lateral Force on Circular Cylinder Using Strings. Journal of Ocean Engineering and Technology, 32(4), 237-243. https://doi.org/ 10.26748/KSOE.2018.6.32.4.237
Bearman, P.W., 2011. Circular Cylinder Wakes and Vortex-induced Vibrations. Journal of Fluids and Structures, 27(5-6), 648-658. https://doi.org/10.1016/j.jfluidstructs.2011.03.021

Blevins, R.D., 2001. Flow-Induced Vibration. 2nd Edition, Van Nostrand Reinhold, New York, USA.

Gustafsson, A., 2012. Analysis of Vortex-Induced Vibrations of Risers. M.Sc Thesis, Chalmers University of Technology, Sweden.

Jung, J.H., Yoon, H.S., 2015. Reynolds Number Effects on Flow over Twisted Offshore Structure with Drag Reduction and Vortex Suppression. Journal of Ocean Engineering and Technology, 29(1), 9-15. https://doi.org/10.5574/KSOE.2015.29.1.009

Kim, S.W., Lee, S.J., Park, C.Y., Kang, D.H., 2016. An Experimental Study of Circular Cylinder's Two-degree-of-freedom Motion Induced by Vortex. International Journal of Naval Architechture and Ocean Engineering, 8(4), 330-343. https://doi.org/10.1016/ j.ijnaoe.2016.05.001

Oh, T.W., 2003. An Experimental Study for the Dynamic Behaviour of Spar. M.Sc thesis, Korea Maritime and Ocean University, Korea.

Park, C.Y., 2017. Experimental Investigation of Vortex- and Wake-Induced Vibration of Tandem Cylinders, M.Sc Thesis, Korea Maritime and Ocean University, Korea.

Silva-Ortega, M., Assi, G.R.S., 2017. Flow-induced Vibration of a Circular Cylinder Surrounded by Two, Four and Eight Wake-control Cylinders. Experimental Thermal and Fluid Science, 85, 354-362. https://doi.org/10.1016/j.expthermflusci. 2017.03.020

Silva-Ortega, M., Assi, G.R.S., 2018. Hydrodynamic Loads on a Circular Cylinder Surrounded by Two, Four and Eight Wake-control Cylinders. Ocean Engineering, 153, 345-352. https://doi.org/10.1016/j.oceaneng.2018.01.116

Son, M.S., 2010. Experiment Study about Decrease Law of Lift Force Acting on Cylinder. M.Sc Thesis, Korea Maritime and Ocean University, Korea.

Srinil, N., Zanganeh, H., Day, A., 2013. Two-degree-of-freedom VIV of Circular Cylinder with Varible Natural Frequency Ratio: Experimental and Numerical Investigations. Ocean Engineering, 73, 179-194. https://doi.org/10.1016/j.oceaneng.2013.07.024 